\title{
State-of-the-art in development of diffuser augmented wind turbines (DAWT) for sustainable buildings
}

\author{
Arouge Agha ${ }^{1, *}$, Hassam Nasarullah Chaudhry ${ }^{1}$ \\ ${ }^{1}$ EGIS, Heriot-Watt University, Edinburgh, UK
}

\begin{abstract}
In this paper, a review of the development of Diffuser Augmented Wind Turbines (DAWT's) into the Built Environment has been presented. DAWT's offer a lot of potential as electricity providers in areas where it is needed, such as in the built environment. Research into DAWT's has revealed that flow along a building significantly affects inlet conditions to the rotor due to flow separation at the leading edge. Adjusting the area ratio, length/diameter ratio as well as diffuser design can improve the performance of the free-standing DAWT significantly. Placing the turbine at the centre of a roof is found to allow the best wind conditions to the wind turbine. It was found that a turbine can be placed at a height 1.3 times the height of a small building for the best results. It has been found that vaulted roof's encourage acceleration of air flow better than other topologies. Furthermore, a recent approach to buildingintegrated wind turbines involves a flow-enhancing architectural design for buildings to improve favourable inlet conditions to a DAWT.
\end{abstract}

\section{Introduction}

With depleting fossil fuel supplies, there is a growing need to address the replacement of our current energy production methods as much as possible. Recent efforts in research have shown realistic power generation techniques from renewable energy are emerging successfully such as power from wind energy, a competitive and efficient alternative to non-renewable power generation. There is an abundance of available wind energy on-shore and off-shore for power conversion. Horizontal Axis Wind Turbines (HAWT) and Vertical Axis Wind Turbines (VAWT) are the most fundamental wind turbine configurations that dominate the wind energy market. The three-bladed HAWT is currently leading the Wind Energy Conversion Systems (WECS) sector, in terms of efficiency, large-scale installation and manufacturing robustness.

The exergetic performance of a HAWT or a VAWT can be improved with the use of passive technology such as a Diffuser (sometimes part of a shroud) to form the Diffuser Augmented Wind Turbine (DAWT). This aerodynamic device can 'funnel' incident air onto a rotor accelerating flow to achieve a greater power extraction for the turbine over a more controllable, continuous period of operation than is currently possible. The Diffuser's

\footnotetext{
* Corresponding author: aa182@hw.ac.uk
} 
capability for effectively capturing incoming wind means it can work in turbulent wind conditions and low speeds which originally made it a uniquely valuable tool in the aerospace industry from aircraft to gas turbine technology. However, the costly additional weight of the Diffuser can be an issue in terms of load bearings. DAWT's can be installed on small to large scales, in the built environment (building integrated) where wind can be turbulent and hard to capture and potentially in open field environments and off-shore applications.

Recently, a multitude of investigations have been performed to assess wind energy potential in built environments. The conclusion from these studies have recommended the use of wind turbines (Ayhan and Sağlam, 2012 [1]; Ishugah et al. 2014 [2]; Toja-Silva et al. 2013 [3]). As Nishimura et al. (2013) [4] explains, understanding the building topologies and velocity profiles available for a given location is crucial. This will identify site-specific locations for the DAWT's. From Computational analysis, it was found that wind flow accelerates through spaces between buildings up to distances of $60 \mathrm{~m}$ after which speeds drop and slowly recover. It was also found that wind flow accelerates up along the free side of buildings reaching the roof. Any wind turbines should therefore be installed behind buildings to capture accelerated flow or along the centreline between buildings. This approach agrees with one of the types of integrated wind turbines discussed by Abohela et al. (2011) [5], where the wind turbine is on free standing tower away from the building. The second type includes building-mounted wind turbines and the third type is where the building is architecturally designed for wind capture.

In line with this, Abohela et al. (2013) [6] conducted a study to identify a roof shape that encourages the best wind profiles. Comparing vaulted, domed, flat, gabled, pyramidal and wedged roofs for a range of wind directions, it was found that the vaulted roof showed the best results especially when flow was parallel to the roof from the side of the building along its curvature. Furthermore, a study on the placement of a HAWT was tested. It was recommended that at a height of $1.3 \mathrm{H}$ ( $\mathrm{H}$ being the height of the building) the turbine should be placed at the midpoint. Similarly, Tabriz et al. (2014) [7] found that small scale wind turbines for a sloped roof with a small inclination angle, are subject to optimum wind conditions at the middle of a roof but given a tall tower the rotor can be placed near the edge of the roof to overcome the turbulent flow and capture skewed flow as it deflects off the edge and along the roof.

In theory, the operational capacity of DAWT's and the wind conditions in most built environments (whether densely urban or not) seems to match well. This paper aims to provide a state-of-the-art review of research and developed approaches to design integration and analysis of DAWT's into the built environment. Section 2 covers computational studies that have been conducted to test and analyse DAWT's based on Horizontal- and Vertical- Axis Turbines for various building applications, in line with the second approach of integrated wind turbine types and Section 3 describes how diffuser aerodynamic design can be used in building design, in line with the third approach of integrated wind turbine types Abohela et al. (2011) [5]. Section 4 introduces some further work with the conclusion in Section 5.

\section{Design-based computational studies for integration of DAWT's into the built environment}

Installing wind turbines in the built environment has an added advantage. Electricity can be supplied where needed and fed into the grid directly (Abohela et al. 2011 [5]). However, since these turbines are often small scale, a collection of turbines may be needed to achieve enough electricity for a given building especially for high-rise buildings and in densely populated areas. With the use of a DAWT, the number of required turbines can be 
decreased, and at higher altitudes it may be possible to better protect the rotor itself from adverse weather conditions. This is subject to the additional weight and loading of the diffuser. Currently, there exists a good selection of commercially available DAWT's. They are nearly all DAWT's based on Horizontal Axis Turbines. Nonetheless, research continues to assess ways of optimising and improving performance through better fluid flow properties. Computational Fluid Dynamic (CFD) analysis provides the best accurate simulation and analysis of air flow through wind turbines. Therefore, most research on DAWT's is CFD based with experimental validation. The examples in this section are for studies that designed and tested DAWT's specifically for the application in the built environment. Therefore the approach differs slightly compared to free standing DAWT's because the presence of building(s) can significantly affect the inflow conditions to the diffuser and so this has to factored into the design.

\subsection{Diffuser action using HAWT's}

There have been many studies on diffuser design and analysis with some of the most comprehensive work starting in the 1970's. Nearly all studies have focussed on the Horizontal Axis Turbine as the rotor. The analysis of literature has bought forward a range of design techniques and computational approaches for enhancing air mass flow through the diffuser, decreasing exit pressures as much as possible (sub-atmospheric), achieving optimum tip-speed ratios, turbine disk loadings and power coefficients. Some studies have now applied theory to the application of DAWT's on buildings.

Wang et al. (2007) [8] conducted a parametric analysis on the optimisation of blade design and rotor design to better suit the conditions of the built environment. A CFD analysis was then performed in a virtual wind tunnel. It was explained that in wind turbines with small rotor diameters, small torques can be achieved posing a problem therefor for starting rotation in low wind speeds common urban areas. A larger torque can be accomplished with an increased number of blades. A 6-bladed rotor with SD2030 airfoil cross section was designed. It was found that the flow and pressure were much higher at the tip than at the root as seen in fig.1, indicating greater torque generation. Different nose cone and nacelle designs were also tested. It was found that the nose and nacelle should be designed for a smallest possible diameter and volume. But this can be hard to achieve as the generator will require adequate space.
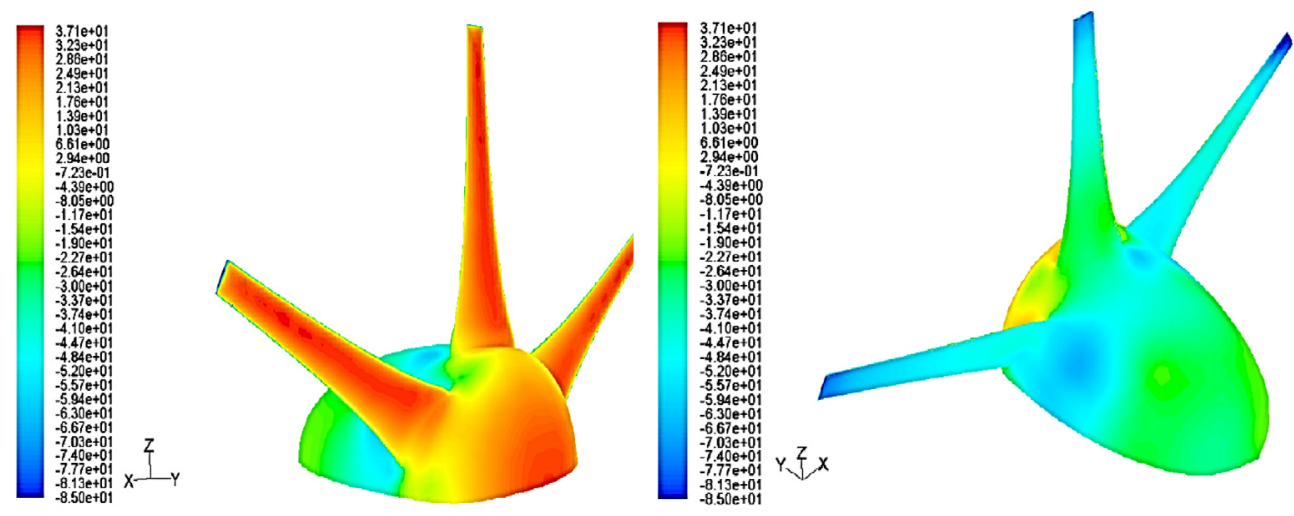

Fig. 1. Contours of Static Pressure (Pa) a) In front of the rotor and b) Behind the rotor (Wang et al. 2007) [8]. 
Wang et al. (2008) [9] then developed a methodology to study the aerodynamics of a small domestic wind turbine with a specially designed shroud for use on building rooftops. A Rutland 913 Windcharger turbine was chosen from tests carried out in a wind tunnel. The pressure distribution and power outputs were measured and validated against a CFD analysis. BEM theory was used to optimise the blades and the DAWT was then reevaluated for its performance in the CFD analysis. The shroud consisted of a converging inlet (concentrator) with large area ratio, a constant diameter test section and a diffuser with smaller area ratio than the inlet. The RNG $k-\varepsilon$ turbulent model and Single Reference Frames (SRF) in GAMBIT and ANSYS Fluent was used for simulation of the virtual wind tunnel. The results showed that the wind speed was increased by a factor of 1.5 through the shroud alone, maximum power augmentation was about 2.2. In all cases there existed an optimum tip speed ratio for every incident wind speed tested. With the addition of the shroud, a $50 \%$ increase in power output was found in low speeds and $25 \%$ in higher wind speed above $10 \mathrm{~m} / \mathrm{s}$, fig. 2 . The results from computational work agreed well with the experimental testing, any errors encountered fell within 5\%. Fig. 3. shows that optimum tip speed ratios were in the range of 4-5 for the DAWT in all computed wind speeds. At lower wind speeds the power coefficient was higher within the optimum tip speed range. And, for a large range of wind speeds, the range for the power coefficients remained quite narrow.
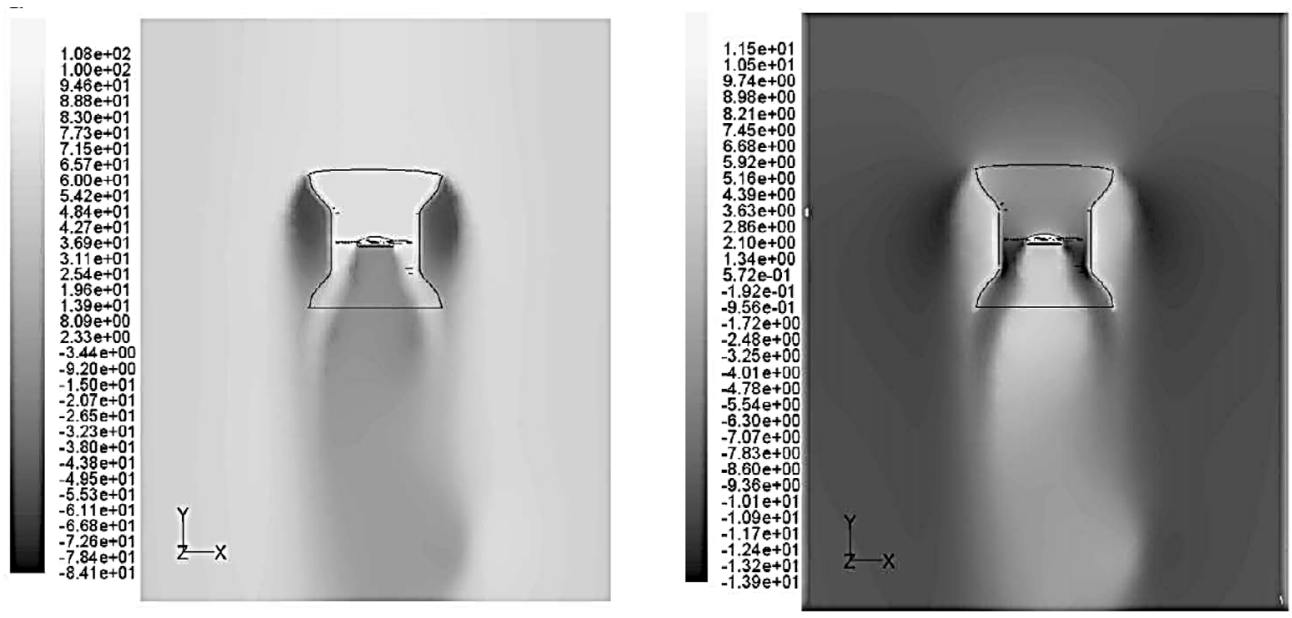

Fig. 2. Result Contours a) Static pressure (Pa) and b) Axial Velocity (m/s) (Wang et al. 2008) [9]. 


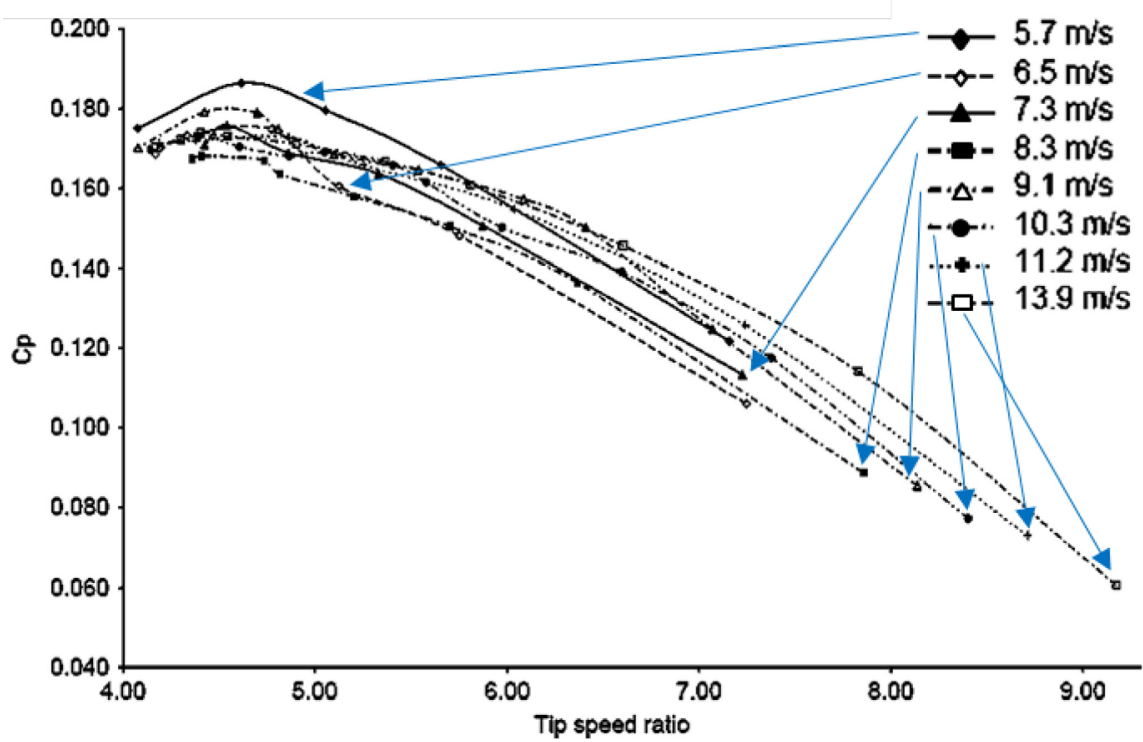

Fig. 3. Computed tip-speed ratio's and power coefficients. (Wang et al. 2008) [9].

Based on work by Abe et al. (2005) [10]; Ohya et al. (2008) [11] and Ohya and Karasudani (2010) [12], Kosasih and Jafari (2014) [13] designed and built a DAWT using the 3-bladed Ampair 300W Turbine. The blades had NACA 63-210 airfoil profiles. The rotor diameter was $190 \mathrm{~mm}$ with length of $120 \mathrm{~mm}$ with a $\mathrm{L} / \mathrm{D}$ of 0.63 , area ratio (outlet to inlet) of 1.61 and diffuser expansion angle of $12^{\circ}$. Tip clearance was kept minimal to 2-3$\mathrm{mm}$. The wind tunnel dimensions were $450 \mathrm{~mm} \times 450 \mathrm{~mm} \times 1500 \mathrm{~mm}$ with wind speed achieving up to $25 \mathrm{~m} / \mathrm{s}$. The DAWT was tested and compared with manufacturer's data and was then simulated in CFD software. Seen in fig.4, the CFD model for the AMPAIR was modelled in a virtual wind tunnel with dimensions $4 \times 10 \mathrm{~m}$ and the rotor diameter was $1300 \mathrm{~mm}$. The maximum power achieved rom the bare turbine was $210 \mathrm{~W}$. It was found that as $\mathrm{H} / \mathrm{D}$ and $\mathrm{L} / \mathrm{D}$ were increased independently, more power was extracted. However, at increasing $\mathrm{L} / \mathrm{D}$ ratio, smaller $\mathrm{H} / \mathrm{D}$ ratios were found to increase power outputs because if both ratios increased there as more flow separation and viscous losses from the diffuser surface. The maximum $C_{p}$ for the bare turbine was 0.257 and with the diffuser the maximum $C_{p}$ achieved was 0.31 for small $\mathrm{H} / \mathrm{D}$ ratios and large $\mathrm{L} / \mathrm{D}$ ratios.
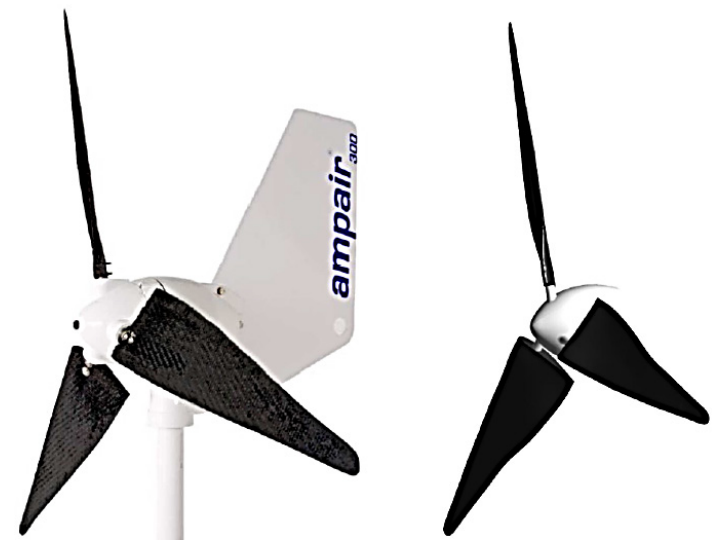

Fig. 4. The AMPAIR 300. Left: Actual rotor and Right: CFD model (Kosasih and Jafari (2014) [13]. 


\subsection{Diffuser action using VAWT'S}

Zanflorin and Letizia (2014) [14] conducted a 2D study on 1.2kW 3-bladed H-Darrieus DAWT in ANSYS Fluent v.15. The URANS (Unsteady Reynolds Averaged NavierStokes) implicit model was used along with the SST (Shear Stress Transport) $k-\omega$ model due to its ability to solve cases with high adverse pressure gradients and simulate detailed vortices exhibited during dynamic tall at low tip-speed ratios. The diffuser dimensions were defined and it was found that the converging section prevented the flow from diverging towards the exit and realigned flow well before the approach to the rotor. The model was then placed on a dual-pitched roof of a building (fig. 5) with height $16.6 \mathrm{~m}$ and an inlet velocity coefficient of 0.35 (typical to urban areas). A $44 \%$ increase in power out was achieved at a speed of $6 \mathrm{~m} / \mathrm{s}$ and a $50 \%$ increase at a wind speed of $10.6 \mathrm{~m} / \mathrm{s}$. To achieve the same results, the turbine installed without the diffuser, would need to be increase through a height of $1 \mathrm{~m}$.

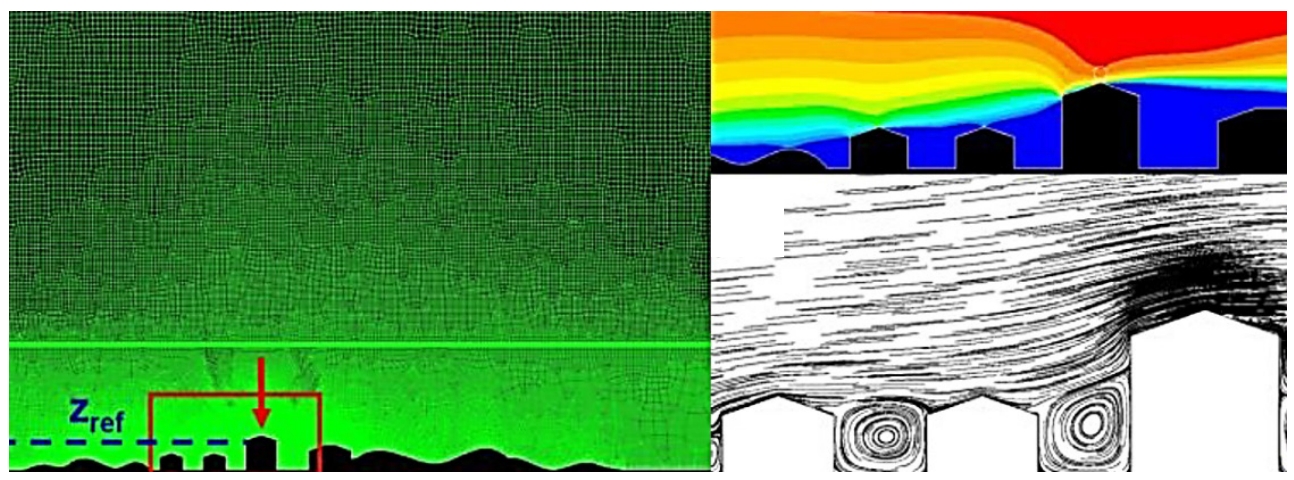

Fig. 5. Left: The red arrow indicates the location of the DAWT, Right: Velocity contours showing accelerated flow towards the top of the dual-pitched roof (Zanflorin and Letizia 2014) [14].

There have also been studies on design DAWT's based on the wind conditions in the built environment for use on existing buildings. One or two studies have been conducted recently that questioned the use of a HAWT inside a diffuser. Krishnan and Paraschivoiu (2015) [15] conducted a 3D CFD analysis of a building integrated DAWT using a vertical axis rotor for the turbine. The most appropriate inlet geometry for the DAWT was assessed leading to a final design. The coefficient of power increased from 0.135 to 0.34 with the use of the shroud and the optimum diffuser inlet angle with reference to the flat roof tested was $5^{\circ}$ as seen in fig.6a). Although the study proved that the addition of the diffuser improved performance of the bare turbine, the power coefficient was below the Betz limit and the augmentation factor was very close to one. The air inlet condition was $6 \mathrm{~m} / \mathrm{s}$ and it can be seen from the final design in fig.6b) (with the turbine's optimum tip-speed ratio at 0.38 ) that the maximum speeds in the turbine were not much higher than the air speed. It can be seen from literature that the use of the vertical axis turbine may not be able to succeed over the use of a horizontal axis turbine in DAWT design. 

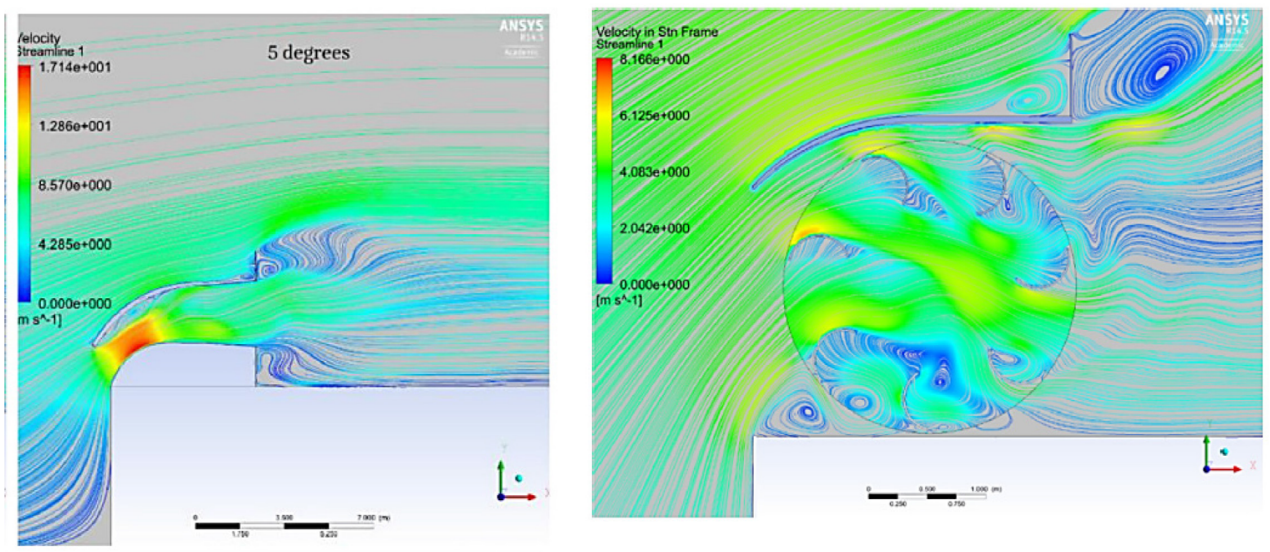

Fig. 6. a) Streamline flow for the $5^{\circ}$ inlet diffuser angle showed the largest maximum velocity compared to $0^{\circ}, 10^{\circ}$ and $15^{\circ}$ and $\mathbf{b}$ ) streamline flow for the final design of the turbine (Krishnan and Paraschivoiu, 2015) [15].

Chong et al. 2013 [16] designed a novel Power-Augmentation-Guide-Vane (PAGV) shroud that covered a Sistan wind turbine. It was integrated into a wind-solar-rain harvester, seen in fig.7). It was designed to aesthetically blend into the building and a mesh would cover the exposed rotors to prevent bird strike. In wind tunnel testing, under freerunning conditions) rotor inertia and bearing friction were applied and it was found that the rpm of the rotor was increased by $75.16 \%$. In a CFD study, torque was increased by 2.88 times and the power output increased 5.8 times at a wind speed of $3 \mathrm{~m} / \mathrm{s}$.

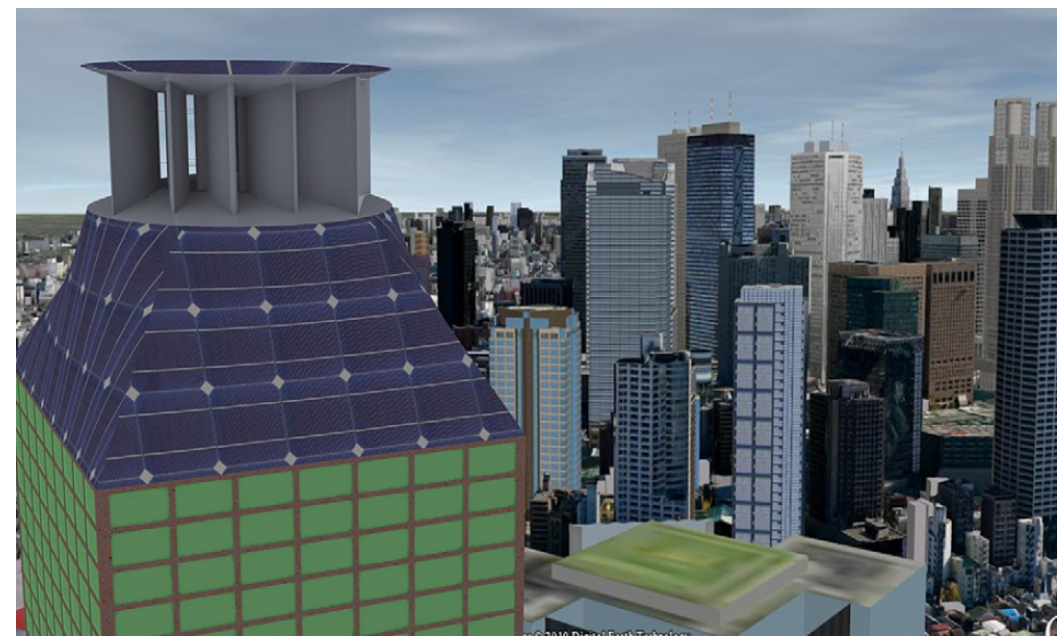

Fig. 7. Computer Aided Design of the PAGV showing its intended roof installation (Chong et al. 2013) [16].

Wong et al. 2014 [17] conducted a 2D study in ANSYS Fluent 14.0 on a DAWT with NACA 0015 blades. Tip-speed ratio was set at 5.1 and velocity $0.091 \mathrm{~m} / \mathrm{s}$ from experimental data. The SST $k-\omega$ model was used with a sliding mesh. The original design for the shroud used four pairs of ODGV (Omni-Directional Guide Vanes) tilted at angles of $20^{\circ}$ and $55^{\circ}$ whereby the outer diameter of the ODGV was twice the rotor diameter of the bare VAWT. The new design divided the guide vanes into two segments ad were bent at an angle of $10^{\circ}$. Torque qualities were significantly improved with the new 
design and the power coefficient increased by $31.65 \%$ compared to the original design and the cut-in speed was reduced. Compared to the bare VAWT, the power coefficient was increased by $147.1 \%$.

\section{Diffuser action in building design}

Fig.8a) shows a conceptual design for the use of a large scale diffuser effect for the built environment. The building is itself, a diffuser. The company, Norwin from Denmark set-up three $225 \mathrm{~kW}, 29 \mathrm{~m}$ diameter rotors between the Bahrain World Centre towers. Each turbine was installed on a dedicated steel frame fixed between the towers as seen in fig.8b) (Smith et al. 2012) [18]. Another example is The Strata in London which is topped with three $9 \mathrm{~m}$ diameter wind turbines, fig.8c). Using aerodynamic building designs almost as if they are diffusers themselves is a very good way of funnelling a larger mass flow of air in the built environment. This potentially means greater power extraction to cover more of a buildings electricity load.
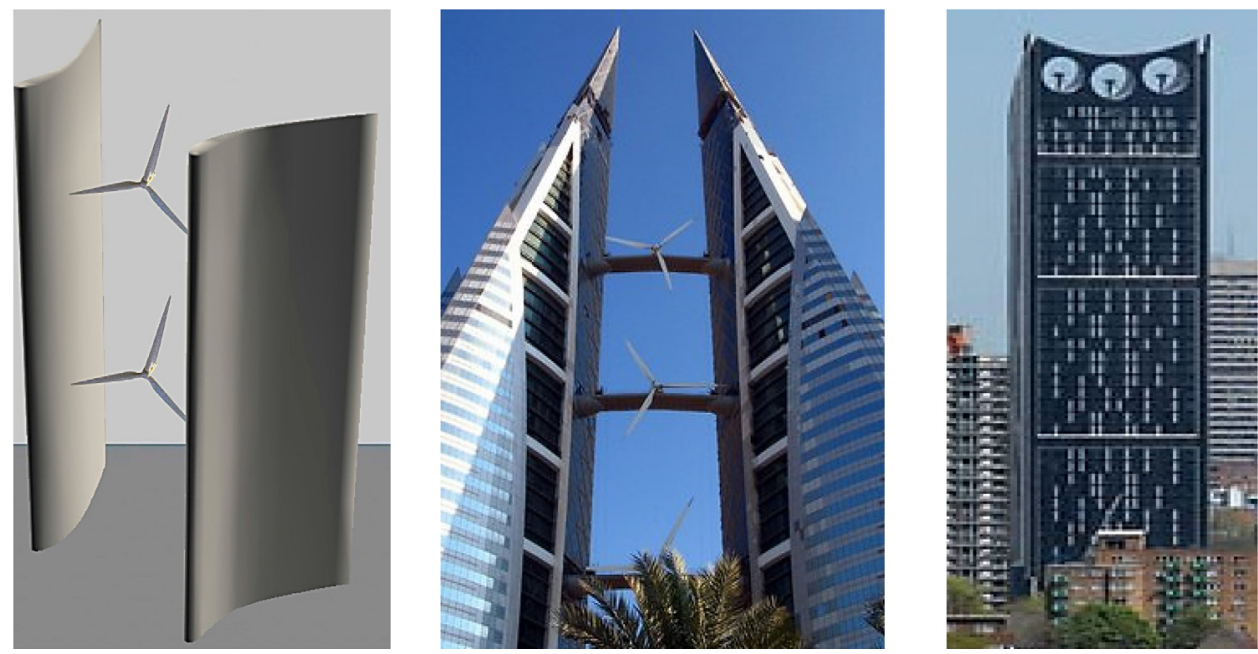

Fig. 8.a) A conceptual aerodynamic design for a building (Mertens, 2006) [19], b) the Bahrain Tower and c) the Strata in London (Smith et al. 2012) [18].

Akesson (2012) [20] produced a feasibility report on the potential to incorporate DAWT's into bridges. E39 is a road that runs along the west coast of Norway with a number of fjords with ferry crossings along its entire length. The fjord crossings range from $1.5 \mathrm{~km}$ to $25 \mathrm{~km}$ in length and have depths reaching down to $1.3 \mathrm{~km}$. Typically, these fjords have suspension bridges, floating bridges and submerged floating tunnels. Based on the design of a 10kW DAWT with a maximum diameter of $3.1 \mathrm{~m}, 215$ turbines were installed per kilometre at 1.5D spacing's, as seen in the drawing in fig. 9). This translates to $80 \%$ of the length of the bridges installed with these turbines. Turbines were installed mainly on two types of bridges, suspension bridges and floating bridges. Turbines were installed in the former at heights of $50 \mathrm{~m}$ and the latter at $10 \mathrm{~m}$. It is stipulated that the DAWT's used cope with turbulent conditions much more successfully than HAWT's typically chosen for this application. They are easier to integrate into the bridge infrastructure, are well protected. To give an example, at the Boknafjord Bridge the installed power is $14.5 \mathrm{MW}$ with local wind speeds between 6 and $8 \mathrm{~m} / \mathrm{s}$. This innovative concept is in its early stages and while it successfully exploits the use of available wind energy, there are a number of structural challenges that need to be addressed. 


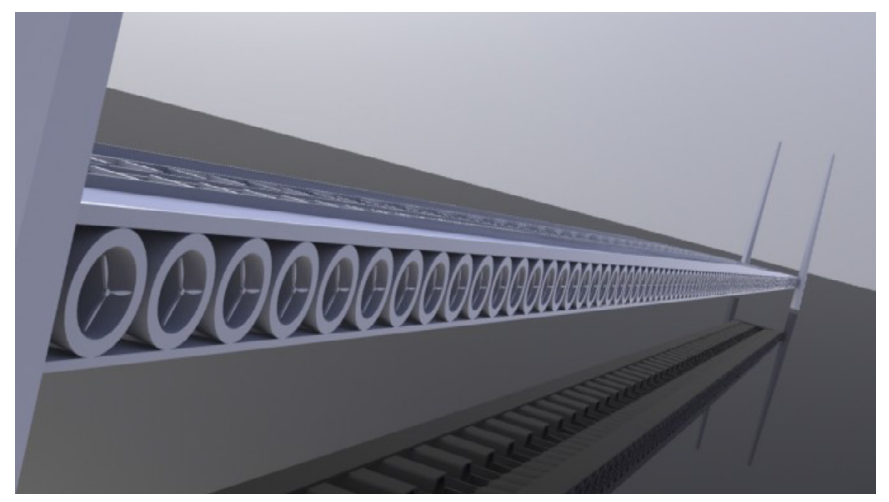

Fig. 9. Computer Aided Design depicting the intended installation of DAWT's below the road of the bridge covering its width and length completely (Akesson 2012) [20].

Watson et al. 2007 [21] conducted a CFD study on two diffusers with similar geometries but with different lengths on a building, seen in fig.10). The model was simulated in ANSYS CFX using the SST $k-\omega$ model because flow separation could be accurately predicted than with the $k-\varepsilon$ model. The building had a half-width of $5 \mathrm{~m}$ and height $3 \mathrm{~m}$. The diffuser inlets in both cases were designed to allow for the smoothest flow possible. The velocity was $5 \mathrm{~m} / \mathrm{s}$. It was found that the building accelerated air along the leading face but separated at the leading edge. The separation point however, was displaced into the inlet of the duct due to its placement at the leading edge. The design of the diffuser inlet depended heavily on being able to transfer the vertical component of the incoming wind to horizontal flow because it would adversely affect efficiencies. Compared to the free-standing diffuser, it was found that for low contraction angles there was a performance drop for the building mounted diffuser due to flow separation along the bottom of the diffuser. It was also found however, that with increasing rotor resistance, performance improved.
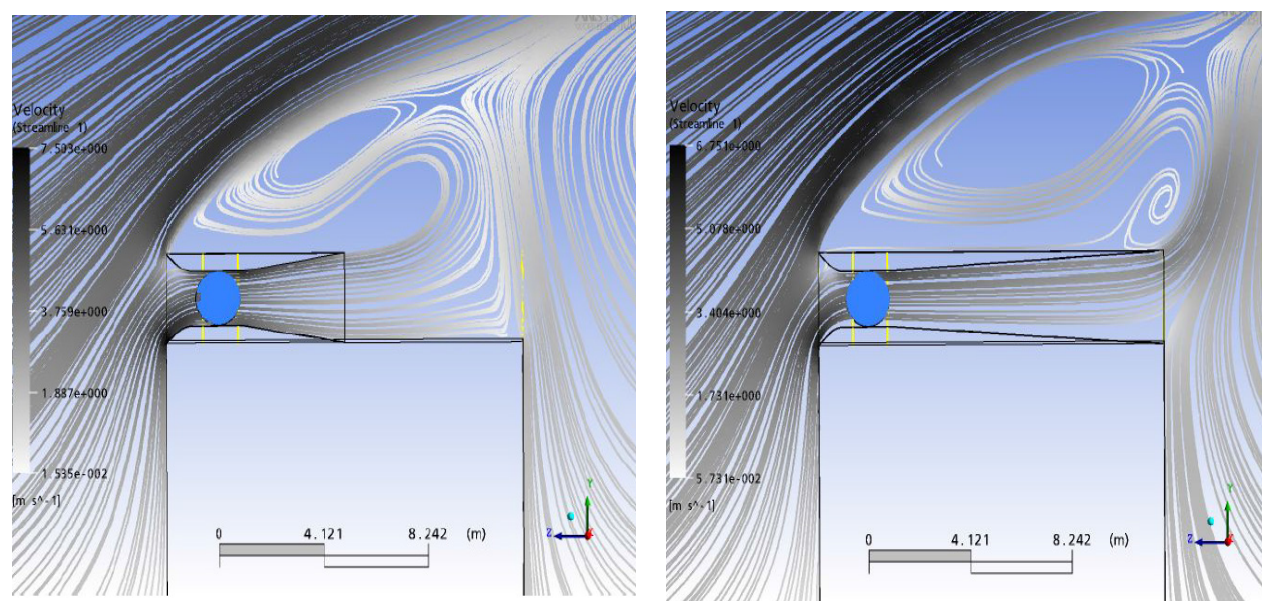

Fig.10. In each case the area ratio was 1.9. a) $C_{p}=1.29$ and b) $C_{p}=1.33$ (Watson et al. 2007) [21].

\section{Further work}

Further work is required in assessing the real difference between the use of Horizontal- and Vertical- Axis Turbines in Diffusers. There haven't been many experimental studies on the 
actual operation of a roof-mounted DAWT. This would address a variety of other factors such as load bearing, fatigue and operational factors of DAWT's in real-time electricity production. An important factor to consider is safety. It has been stipulated many times in literature that compared to conventional WECS, DAWT's are considered safer due to their smaller size, protecting shroud, lower rpm and larger number of blades Kosasih and Tondelli (2012) [22]. So bird and bat strikes are anticipated as highly unlikely which is especially favourable considering the implementation of DAWT's into the built environment. There have not as yet been any studies in this area.

Below are the results from two case studies conducted by the author, modelled under steady state, free stream conditions. The wind speed used $9.1 \mathrm{~m} / \mathrm{s}$. The RNG $k-\varepsilon$ model was chosen with standard wall function. The streamlines show strong vortices that formed in the wake of the shroud for the DAWT case in fig.11a). This implies a drop of pressure as energy is extracted. This should therefore have the effect of pulling in more air mass flow through the shroud. This is similar to the B-DAWT (Building-DAWT) in fig.11b) where the flow is accelerated. However, the flow seen is not symmetrical for the B-DAWT as it is for the DAWT. Due to the presence of the building, the air flow is forced to change direction bending as it reaches the roof edge. This means the air doesn't flow directly into the shroud and the flow pattern for the B-DAWT shows larger acceleration along the bottom half of the inner shroud volume. In both cases, the increase in wind speed was around $47 \%$ based on the maximum velocity computed at the rotor. The augmentation factors were computed as 2.46 for the DAWT and 1.38 for the B-DAWT compared to the benchmark bare rotor.
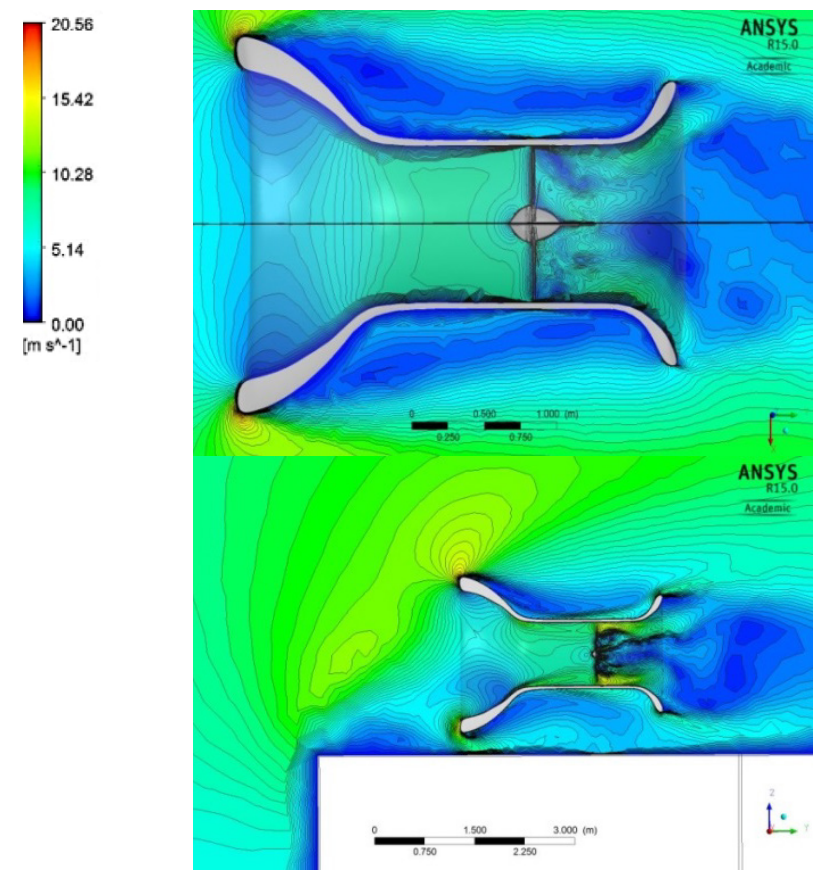

Fig. 11. Velocity Contours. Air flow is from the left. a) DAWT and b) B-DAWT.

\section{Conclusion}

Due to its aerodynamic shape the diffuser can accelerate air mass flow through a rotor thereby enabling greater power extraction. Many parametric and experimental studies have 
been performed for a range of diffuser parameters and different methodologies for making performance assessments are available. The uses of CFD simulations are crucial to accurately simulating flow at low cost. It is a flexible tool that is useful for optimisation exercises especially when many different parameters are involved. It can be concluded from literature so far that in the application of a DAWT to a building, the design of the diffuser is specific to the chosen rotor and the rotor chosen can be specific to the location of the building due to the wind conditions it sits in. Where possible, a building can be aerodynamically designed to encourage better flow conditions into the DAWT inlet and the diffuser can then be designed accordingly to the specifications of the rotor. In this way, a DAWT can be installed to its optimum operating conditions with material, loads on the turbine system and costing permitted.

The study presented has been supported by the funding from Heriot-Watt University, at the School of Energy, Geoscience, Infrastructure and Society.

\section{Nomenclature}

$\begin{array}{ll}C_{p} & \text { Power Coefficient } \\ \varepsilon & \text { Turbulent Dissipation Rate } \\ D & \text { Diffuser Diameter } \\ H & \text { Flange Height } \\ k & \text { Turbulent Kinetic Energy } \\ L & \text { Length of Diffuser } \\ P & \text { Power } \\ P & \text { Pressure } \\ V & \text { Velocity } \\ \omega & \text { Specific Dissipation Rate }\end{array}$

\section{References}

1. D. Ayhan, and Ş. Sağlam, "A technical review of building-mounted wind power systems and a sample simulation model." Ren. Sust. Energy Rev. 16(1): 1040-1049, (2012).

2. T. F. Ishugah, et al. "Advances in wind energy resource exploitation in urban environment: A review." Ren. Sust. Energy Rev. 37: 613-626, (2014).

3. F. Toja-Silva, et al. "Urban wind energy exploitation systems: Behaviour under multidirectional flow conditions - Opportunities and challenges." Ren Sust. Energy Rev. 24: 364-378, (2013).

4. A. Nishimura, et al. "Wind Turbine Power Output Assessment in Built Environment." Smart Grid Ren. Energy 04(01): 1-10, (2013).

5. I. Abohela, et al. "Urban wind turbines integration in the built form and environment." FORUM Ejournal, School of Architecture, Planning and Landscape, Newcastle University, UK 10: 23-39, (2011).

6. I. Abohela, et al. "Effect of roof shape, wind direction, building height and urban configuration on the energy yield and positioning of roof mounted wind turbines." Ren. Energy 50: 1106-1118, (2013).

7. A. B. Tabrizi, et al. "Performance and safety of rooftop wind turbines: Use of CFD to gain insight into inflow conditions." Ren. Energy 67: 242-251, (2014).

8. F. Wang, et al. "Development of small domestic wind turbine with scoop and prediction of its annual power output." Ren. Energy 33(7): 1637-1651, (2007). 
9. F. Wang, et al. "The methodology for aerodynamic study on a small domestic wind turbine with scoop." J. Wind Eng.Ind.Aero. 96(1): 1-24, (2008).

10. K. Abe, et al. "Experimental and numerical investigations of flow fields behind a small wind turbine with a flanged diffuser." J.Wind Eng. Ind. Aero. 93(12): 951-970, (2005).

11. Y. Ohya, et al. "Development of a shrouded wind turbine with a flanged diffuser." J. Wind. Eng. Ind. Aero. 96(5): 524-539, (2008).

12. Y. Ohya, and T. Karasudani, "A Shrouded Wind Turbine Generating High Output Power with Wind-lens Technology." Energies 3(4): 634-649, (2010).

13. B. Kosasih, and S. A. Jafari, "High-Efficiency Shrouded Micro Wind Turbine for Urban-Built Environment." Appl. Mech. and Mat. 493: 294-299, (2014).

14. S. Zanflorin and S. Letizia, "Improving the performance of wind turbines in urban environment by integrating the action of a diffuser with aerodynamics of the rooftops" Energy and Procedia 82: 774-781, (2015).

15. A. Krishnan and M. Paraschivoiu "3D analysis of building mounted VAWT with diffuser shaped shroud." Sus. Cities. Society 27: 160-166, (2015).

16. W. T. Chong et al. "Performance investigation of a power augmented vertical axis wind turbine for urban high-rise application." Ren. Energy 51: 388-397, (2013).

17. K. H. Wong, et al. "The Design and Flow Simulation of a Power-augmented Shroud for Urban Wind Turbine System." Energy Procedia 61: 1275-1278, (2014).

18. J. Smith, et al. "Built environment wind turbine roadmap". Colorado, USA, National Renewable Energy Laboratory (NREL): 1-58, (2012).

19. S. Mertens, "Wind Energy in the Built Environment - Concentrator Effects of Buildings", Delft University of Technology: 1-180, (2006).

20. L. Åkesson, "Technology survey for renewable energy- Integrated to bridge constructions. Statens vegvesens", SP Technical Research Institute of Sweden: 1-43, (2012).

21. S. J. Watson, D. G. Infield, J. P. Barton, S. J. Wylie, "Modelling of the Performance of a Building-Mounted Ducted Wind Turbine" J. Phys. Conf. Seris 75:1-10, (2007).

22. B. Kosasih and A. Tondelli "Experimental Study of Shrouded Micro-Wind Turbine." Procedia Eng. 49: 92-98, (2012). 